\title{
The Short-Term "Bridge Model” Study Abroad Program: Peacebuilding in Latin America
}

Jeffrey D. Pugh, Providence College and Center for Mediation, Peace, and Resolution of Conflict

ABSTRACT The conventional wisdom about political science international education assumes that students choose between short "island" study abroad programs that are accessible but have only superficial impact, and longer immersion programs, achieving a greater effect. This article argues that well-designed study abroad programs can combine the best of both models to achieve significant impact even in a short program. It proposes a "bridge model" for reconceptualizing study abroad not as a discrete event with more or less impact on student learning, but as a key intervention that furthers a student's overall development within an internationalized curriculum. The article examines the case of a peacebuilding study abroad program in Ecuador. It measures alumni perceptions of impact, objective outcomes, and alumni network development. The key finding is that solid program design and structured cross-cultural interaction produces the type of long-term effect and networks traditionally associated with immersion programs.

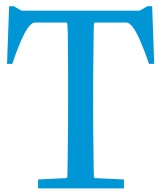

he emphasis within political science on student civic engagement and internationalization of the curriculum during the past two decades (Battistoni 1997; Jacoby and Brown 2009) has coincided with a drastic increase in the number and diversity of international academic experiences that go beyond the traditional "island" model of study abroad. Among these, experiential programs designed to teach international conflict resolution and peace studies have proliferated, combining theoretical training in conflict analysis and peace studies with a practical application of mediation and negotiation skills, and, sometimes, international development (Fowler 2005). ${ }^{1}$

The growth of these programs raises a broader question about the effectiveness of this mixed experiential pedagogy not only on student learning and attitudes but also on concrete educational and professional outcomes. This article argues that well-designed shortterm study abroad programs can achieve significant impact traditionally associated with semester or longer immersion programs but accomplishing this in a more accessible way for a broader and more diverse student population. The article proposes a frame-

Jeffrey D. Pugh is assistant professor of political science at Providence College and executive director of the Center for Mediation, Peace, and Resolution of Conflict. He can be reached atjpugh@providence.edu. work for understanding short-term programs as key interventions that "bridge" different elements of a student's overall internationalized education. The empirical portion of the article analyzes the case of the Peacebuilding and Development Study Abroad Program in Ecuador (PADSAPE), a short-term program with local cultural immersion and experiential-learning components. It explores the relationship between student participation in PADSAPE and longer-term personal development and impact, including the development of useful skills, subsequent in-depth international experiences, and transnational professional networks.

The analysis reveals that the value of short-term programs is not only students' immediate knowledge and skills transfer, but also their ability to bridge between past international affairs academic preparation and future in-depth practical experiences abroad. Thus, the case study serves as a useful guide for an institution seeking to internationalize its curriculum and to prepare students with both knowledge and professional skills and networks to help them successfully enter an international career.

\section{THE PROGRAM DURATION DEBATE: ACCESSIBILITY} VERSUS IMPACT

Much has been written about the need to prepare today's students for an increasingly globalized and interconnected world by 
"internationalizing the curriculum" and equipping students with the ability and awareness to engage as global citizens (Fobes 2005; Jacoby and Brown 2009). In fact, the APSA Task Force on Political Science in the 21st Century argued that "Political science should continue to internationalize its curriculum by ... emphasizing global citizenship that connects what is local and what is global and stresses the importance of breaking away from a purely Westernized view of the world" (Fraga, Givens, and Pinderhughes 2011, 3-4). The literature has recognized the positive effect that international education can have on students even years after their experience. According to the Study Abroad for Global Engagement (SAGE) survey of more than 6,ooo former study abroad participants from 22 institutions over more than 20 years, $83.5 \%$ of respondents reported that study abroad had a strong influence on their lives, changing their behaviors more than any other college activity (Paige et al. 2009, $\mathrm{S}_{3} 6$ ).

These results indicate the significant potential of study abroad to promote long-term global citizenship and civic engagement. Yet because only $10 \%$ of the SAGE respondents participated in one- or two-month programs, the evidence is less clear whether shortterm international experiences can have significant long-term effects. This is a perennial question in the debate about study abroad: many studies note that greater accessibility (in cost, language, and time) make short-term island programs feasible for a more diverse student population, yet the long-term immersion model is often assumed to lead to higher levels of cross-cultural competency, emotional intelligence, and engagement as global citizens (Davidson 2007; Dwyer 2004). The literature has largely implied a choice between accessibility and impact, indicating that the two goals are directly opposed (Fry et al. 2009; Kuo and Fehr 2011).

The expansion of study abroad has led to an increase in shortterm programs combined with a $50 \%$ decrease in the proportion of year-long international educational experiences (Institute 2011). This trend has concerned some observers, who argue that shortterm study abroad programs have high "market appeal" but often promote only superficial contact with host societies and limited long-term impact (Engle and Engle 2003, 2-3). Despite arguing that year-long immersion programs have the greatest impact, one large- $\mathrm{N}$ retrospective longitudinal survey of former study abroad participants concedes intriguingly

Well-planned, intensive summer programs of at least 6 weeks duration can have a significant impact on student growth across a variety of important outcomes. While it requires very careful educational planning, expert implementation, and significant resources to achieve these outcomes in a shorter-term length, the results of this study should encourage study abroad educators and should reinforce the value of short-term programming of at least 6 weeks duration. Whether these results would hold for the increasingly popular 1-5 week programs is unknown (Dwyer 2004, 161).

A case study of one such short-term program follows.

\section{CASE STUDY: PEACEBUILDING AND DEVELOPMENT STUDY ABROAD IN ECUADOR (PADSAPE)}

To examine empirically the strengths, weaknesses, and lessons learned in the design of short-term study abroad programs that seek to go beyond the traditional island model, this article focuses on the case of PADSAPE, a 3.5-week summer program that has been co-led by the author and faculty from a large southern US university since 2007. This is an example of a niche program organized around a specific theme (peace, conflict, and development). All students participate in the same program activities together, in contrast to omnibus programs in which students divide up and take different classes with individual faculty members. Between 15 and 20 undergraduates participated in the program each year (including three or four Ecuadorian college students, or "host fellows," who are selected through an open competition). The program involves close partnership in the logistics, program design, and service-learning components with a nongovernmental organization (NGO) based in Quito (directed by the author) that carries out grassroots peacebuilding work in Ecuador.

Program participants benefited from a more diverse learning environment than typical study abroad programs at the sponsoring 
university, with a nonwhite student proportion of $46 \%$ (compared to $18 \%$ for overall study abroad participation at the university and $20 \%$ for participants on the university's other trips to Latin America). ${ }^{2}$ The program was designed with the explicit purpose of overcoming the limitations of the island model program while maintaining the accessibility of a short-term and cost-effective format. Therefore, its program design reflects what I call the "bridge model" for study abroad, which conceptualizes a shortterm program not as a discrete event with more or less impact on student academic, personal, and professional growth, but as a key intervention in a larger process of global learning across the curriculum (see figure 1).

PADSAPE acts as a bridge between the value and accessibility of short-term programs and the effectiveness and personal and professional growth associated with longer-term immersion programs. Several core design elements facilitate the program's “bridging" function. The Ecuador program is accessible to students even if they do not yet speak the local language and even if they are prevented by time or financial ability from committing to a fullsemester abroad. At the same time, the incorporation of local students, experiential simulations, in-depth site visits, dialogue with local practitioners, and opportunities to use Spanish in professional settings for those who do possess language skills all increase cross-cultural competency and motivate students to pursue longerterm international opportunities after the program.

A second bridging function occurs in spanning the theorypractice divide. By explicitly linking international affairs concepts and theories to practical service learning and professional
Within the context of study abroad ... cooperative learning, dialogue, and constructive conflict cannot be restricted only to the community of learners themselves but must involve diverse members of the host community, as people from the host culture are the true experts regarding their own lives and culture. Hence, collaborative learning in the international context should mean the inclusion of diverse members of the host culture-including people with opposing or conflicting viewpoints-in both the definition of problems which serve as the core of the learning and in the critical analysis of such problems (2002, 58-59).

The field visits, in particular, are designed to promote relationship building and practical understanding by bringing students to the sites of actual peacebuilding work and facilitating dialogue with people who have been affected by conflict or have been active in seeking peaceful change. According to one former student, "The visits to the field broaden horizons, engender a global perspective, and make one excited to explore and interact with the world abroad."

\section{EVIDENCE OF PROGRAM IMPACT-ALUMNI PERCEPTIONS}

To measure whether the program model accomplished its goals, I conducted an online survey of past participants from the first four years in which PADSAPE ran in Ecuador. I successfully contacted 62 of 66 program alumni, with a response rate of $56 \% .^{3}$ The survey measured perceptions of the program and its impact and academic and professional outcomes, as well as a question about networking after completing the program. It also allowed

\section{"I am currently producing media for research and social activism and my experience in Ecuador, particularly studying the impact of media on peace relations ... greatly shaped the position I am in today."}

development, the program equips students with skills that prepare them for international careers. In particular, the practical negotiation skills gained through training and simulations, as well as the portfolio of "deliverables" that students produce through their service learning projects, continue to help them after the program. One survey respondent observed that "the service learning project has the biggest comparative advantage over traditional classroom settings." Another alumnus drew a direct link between his service learning experience and his ultimate professional direction: "I am currently producing media for research and social activism and my experience in Ecuador, particularly studying the impact of media on peace relations ... greatly shaped the position I am in today." In addition to knowledge and skills transfer, the relationships among participants with the people they meet through the program establish transnational networks that increase participants' cross-cultural understanding and give them access to useful professional contacts. The program design includes dialogue with Ecuadorian practitioners, field visits, and simulations that encourage students to understand and respond effectively to others in cultural or political contexts that are different from their own experience. The pedagogical design of the program aligns with the analysis of Lutterman-Aguilar and Gingerich: for qualitative comments and included an open-form question asking respondents to identify which program design aspect (if any) had been the most helpful for their longer-term personal and professional development, and why.

Despite being a short-term program, PADSAPE has had a significant effect on its alumni and has allowed them to build critical skills and global competencies. The survey asked students to compare the study abroad program to a traditional class across a series of impact areas using a 5-point Likert scale. According to table 1, the largest effect came from the cross-cultural skills, with more than $90 \%$ of respondents reporting that the program provided opportunities to develop cross-cultural interaction skills more than a traditional class (and 78\% reporting "much more" than a traditional class). Qualitative responses reinforced this point, and many students credited the Ecuadorian host fellows with making this possible. One former student said that the cross-cultural interaction was "better than the three other study abroad programs I've been on (some three times as long)."

Some $88 \%$ of respondents reported that the program provided opportunities to apply what they learned in a practical setting more than in a traditional class on campus. The negotiation simulations, field visits, and service-learning components were the primary program design aspects that students associated with this 
Table 1

\section{Alumni Perceptions of Program Impact}

\begin{tabular}{|c|c|c|}
\hline $\begin{array}{l}\text { COMPARE THIS STUDY ABROAD PROGRAM TO TRADITIONAL CLASSES AT YOUR HOME CAMPUS } \\
\text { (1 = MUCH LESS THAN A TRADITIONAL CLASS, } 5 \text { = MUCH MORE THAN A TRADITIONAL CLASS) }\end{array}$ & MEAN & MODE \\
\hline Provided opportunities to apply what you learned in a practical setting & 4.48 & 5 \\
\hline Provided opportunities to develop cross-cultural interaction skills & 4.88 & 5 \\
\hline Taught knowledge and skills that would be useful for your professional development & 4.04 & 4 \\
\hline Provided opportunities to meet people who would be useful professional contacts & 3.84 & 4 \\
\hline Influenced your subsequent academic or career decisions & 4.12 & 4 \\
\hline Deepened your understanding of peace and the processes for achieving it & 4.36 & 5 \\
\hline
\end{tabular}

Table 2

\section{Concrete Outcomes for Program Alumni}

\begin{tabular}{|c|c|c|c|}
\hline $\begin{array}{l}\text { HAVE YOU HAVE DONE ANY OF THE FOLLOWING IN THE TIME SINCE YOUR PARTICIPATION } \\
\text { IN THE STUDY ABROAD PROGRAM? }\end{array}$ & YES & NO & DK/NA \\
\hline Lived abroad for more than 3 months & $31 \%$ & $66 \%$ & $3 \%$ \\
\hline Improved your Spanish-language skills & $41 \%$ & $31 \%$ & $28 \%$ \\
\hline $\begin{array}{l}\text { Pursued graduate education in international affairs, peace, conflict, development, } \\
\text { or a related field }\end{array}$ & $39 \%$ & $45 \%$ & $16 \%$ \\
\hline $\begin{array}{l}\text { Participated in an 'organized international experience', including an internship } \\
\text { or volunteer trip abroad, an international job, research, other study abroad, } \\
\text { Peace Corps, etc. }\end{array}$ & $55 \%$ & $39 \%$ & $6 \%$ \\
\hline $\begin{array}{l}\text { Used your service learning project as part of portfolio to get into grad school, attain } \\
\text { a job or internship, or get a scholarship }\end{array}$ & $50 \%$ & $37 \%$ & $13 \%$ \\
\hline $\begin{array}{l}\text { Participated in public advocacy or a campaign designed to promote issues of peace } \\
\text { and social justice }\end{array}$ & $28 \%$ & $66 \%$ & $6 \%$ \\
\hline
\end{tabular}

provides evidence for the bridging phenomenon and challenges the traditional assumption that study abroad programs must require intensive language preparation to have any lasting influence on language acquisition. Allowing nonspeakers to participate exposes them to Spanish and motivates them to learn more, which they might not do if they had been blocked from participation by language prerequisites. The data in table 2 underrepresent the degree of continued language learning, because many program participants were already fluent or native speakers. Of those who were not already fluent, $57 \%$ of respondents improved their Spanish-language skills after participating in the program.

Other concrete outcomes were reported by program alumni as well. The solid majority (55\%) of respondents went on to participate in a more in-depth "organized international experience." In addition, $46 \%$ reported that they had pursued graduate education in international

outcome. For example, one respondent reported, "The field visits allowed me to see that the issues discussed were ongoing and affecting real people. This has strengthened my resolve to get involved in programs pertaining to peace and development." Another respondent stated, "The mediation and conflict resolution simulations and the internship part have given me contacts, experience in a field, and work experience." The other major impact was in-depth content knowledge about conflict resolution and peace. Some $88 \%$ of respondents reported that the program deepened their understanding of peace and the processes for achieving it more than a traditional class.

\section{EVIDENCE OF "BRIDGING" IMPACT-CONCRETE OUTCOMES}

Subjective perceptions about the program from alumni are useful in measuring the program's effectiveness, and they are often the focus of postprogram evaluations. Because the concept of the bridge model reflects the idea that a study abroad program can be a stepping stone or turning point in a larger process of internationalized education, however, I wanted to know what types of subsequent concrete outcomes occurred. As seen in table 2, participation in this short-term study abroad program seemed to be associated with several longer-term professional and academic outcomes.

The finding that a large proportion of program alumni are motivated to continue improving their Spanish-language skills despite that fluency is not a prerequisite for participation affairs or a related field (excluding those who responded "not applicable," because they are likely recent participants who had not yet graduated). Evidence of the professional benefits can be found in the $50 \%$ of respondents who reported that the "deliverable" from their mini-internship project helped them to get into graduate school, obtain a job, or receive a scholarship. These concrete outcomes provide a more nuanced picture of how the bridging function works than could be captured by an immediate postprogram evaluation. Although comparison data asking these same questions of students on long-term programs are not available, a survey of more than 600 CIEE study abroad alumni in which $74 \%$ had participated in programs of at least four months provides some suggestive comparisons. It found that $33 \%$ of the responding alumni had participated in a subsequent organized international experience, and $63 \%$ went on to pursue graduate education in any field, not only international affairs (Fry et al. 2009). On both measures, the short-term Ecuador program compares favorably to these outcomes for longer-term programs.

\section{TRANSNATIONAL SOCIAL CAPITAL AND NETWORKS}

In addition to traditional outcomes such as skills, knowledge, and motivation, study abroad programs also play a key role in building professional networks that transcend borders. Study abroad allows for fulfilling personal relationships and a more globalized conception of one's social network, and this transnational social capital can be a valuable professional resource during and after 


\section{Program Alumni Network Showing Relational Ties}
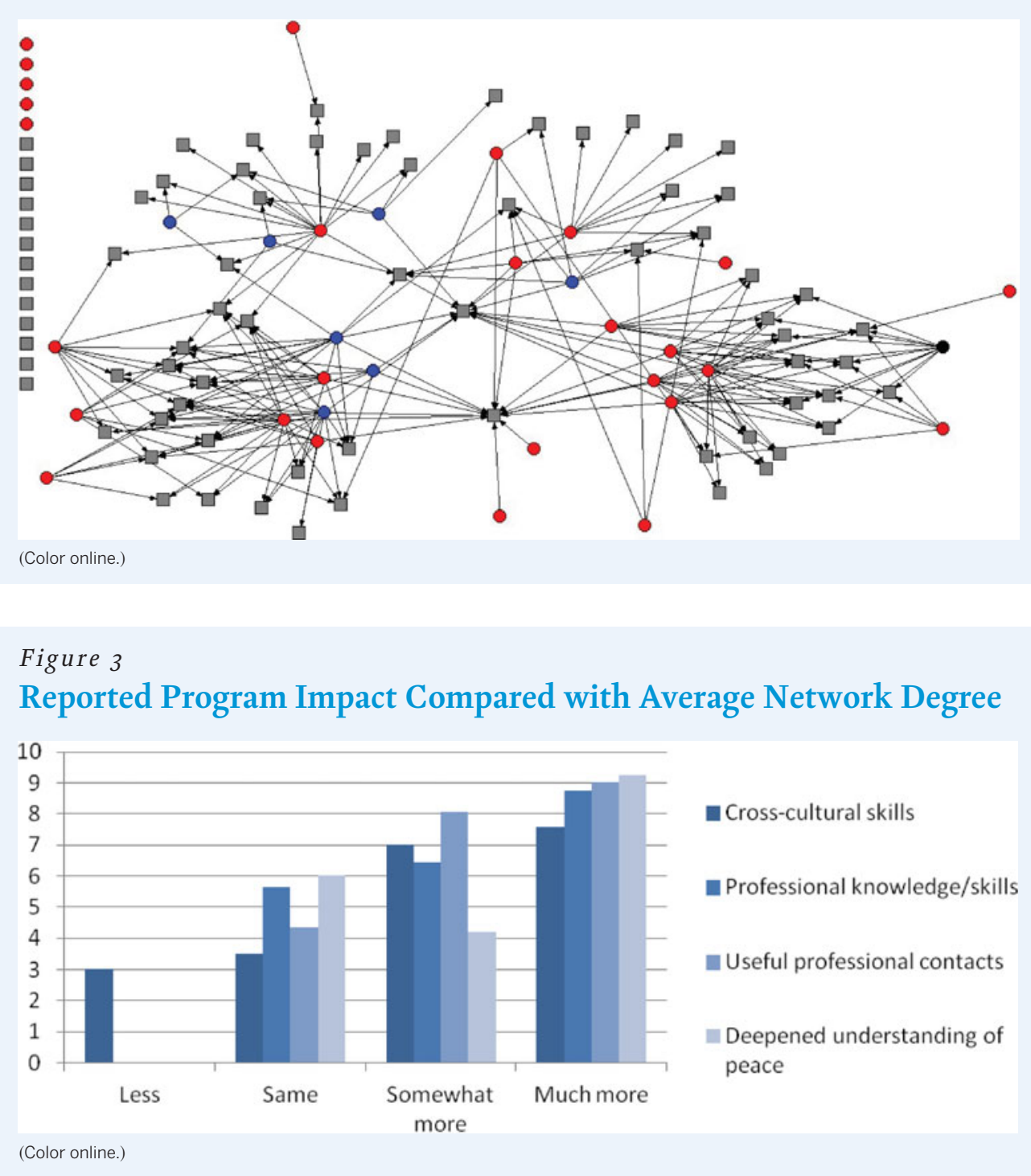

in contact with being represented by the square nodes. The lines represent the presence of a reported contact link between the two people. Several features of the alumni network structure become immediately apparent. Four major subnetwork clusters represent the four years that the program ran during the study period. Obviously, students are more likely to meet, and therefore to stay in touch with, other students who participated at the same time as they did. The two nodes in the middle of the network with the most linkages to all four clusters represent the two primary faculty members. There is also variation in how dense each of the clusters is: the two most recent years (the two bottom clusters in the network) are more densely connected than the earlier years at the top of the network. Because relationships sometimes fade with time, this is understandable although it is worth noting the significant number of social ties that still exist even among the participants in the 2007 study abroad program (located in the top right cluster of the network).

Network analysis helps identify the factors that help build and maintain transnational ties and especially the ties that can lead to the college. PADSAPE intentionally facilitated this networking through introductions to guest speakers, a reception that included Ecuadorian and American attendees, the establishment of alumni Facebook pages, and newsletters from the NGO partner in Ecuador. The Ecuadorian host fellows provided an essential catalyst for the formation of lasting transnational networks. As one respondent explained, "Our host fellows were some of my first and closest 'international' friendships and were the conduits for intercultural exchange." To measure the relation between program participation and the structure of networks, the survey included a roster of all program alumni and faculty and asked respondents to indicate those with whom they had maintained contact, as well as those whom they had given or received professional assistance (such as information for a project, travel assistance, job leads, etc.). This relational data was then analyzed using UCINET software, which produced the visual representation in figure 2 .

Because the survey was anonymous, figure 2 is a two-mode network sociogram, with the survey respondents being represented by the round nodes, and the people they reported staying exchange of professional assistance among alumni. Here again, the host fellows appear to be playing a key role. If one counts the number of ties that each respondent maintained with other participants after the program (i.e., whether they have kept in touch or exchanged professional help), this number is the network degree for that respondent.

Survey respondents are represented by the round nodes, and the people they report maintaining contact with are represented by the gray square nodes. A line between a square and a round node represents a contact tie. The Ecuadorian host fellows tend to be more central in the network and more densely tied with other students (7.86 relational ties vs. 6 for US students), and, in addition to the faculty, they help bridge between the different programyear clusters, since some of the host fellows from different years know each other and help to introduce their classmates. This results in expanded transnational networks for the US students as well.

The PADSAPE program model bridges between US and Ecuadorian students to create transnational networks that are 
useful for academic and professional development. One US alum, after becoming a documentary filmmaker, reestablished contact with one of the guest speakers and one of the host fellows from the program for advice both on a specific conflict that had been studied during the program and for more general professional advice. An Ecuadorian host fellow who had been accepted to a US internship program reached out to several of his former US classmates who lived in the area to ask about suitable places to live and advice on what to bring, and then met with them on arrival. These are only two examples of the transnational social capital produced through the alumni network depicted in figure 2.

Some correlation exists between students' average number of network ties (degree) and their perception of program impact compared to traditional classes, as shown in figure 3. Particularly in the case of cross-cultural skill development and gaining useful professional contacts, those who reported that the program had "much more" impact than a traditional class tended to be more networked than students who reported less impact. Students who reported that their internship deliverable helped them professionally also had a higher average degree of network connectivity (8.19 connections) than those who did not ( 6.75 connections). Although this data is insufficient to show causality, it suggests a relationship between benefits gained from the program and high levels of networking even years after completing the program.

\section{CONCLUSION}

Short-term study abroad programs can have significant longerterm impact on students' professional and personal development, their development of useful transnational networks, and their peacebuilding capacities, and program length and intensity may not be as simple an explanation for impact as it seems. Although the topic-specific nature of the program in Ecuador and the small sample size of the alumni survey respondent pool (and the lack of a control group) require us to use caution in generalizing results to other study abroad programs, nonetheless, this detailed case study shows that innovative program design can form an educational "bridge" that leads to more in-depth international experiences, greater professional and personal development, and helpful professional and personal contacts that continue to benefit students years after their participation. This is a key step in developing future global citizens with the awareness, skills, and motivation to address complex transnational problems peacefully and effectively, which is one of the stated goals of many campus international education initiatives.

\section{ACKNOWLEDGMENTS}

Thanks to Rick Battistoni, Joe Cammarano, Ling Chen, Patricia Sullivan, the attendees of a 2011 APSA presentation and a 2012
MACLAS panel, and the anonymous $P S$ reviewers for helpful feedback on earlier drafts of this article. Thanks to Magali GarciaPletsch, Ethan Gentes, and Lizeth Gonzalez for their research assistance.

\section{NOTES}

1. By one recent count, there were more than 140 such programs specifically targeted toward peace and conflict, with over a dozen programs in Latin America. See http://www.cemproc.org/peaceSA.htm for this list.

2. Office of International Education statistics at the sponsoring university; Thanks to Kasee Laster of OIE for providing overall university study abroad participant race/ethnicity data disaggregated by region.

3. The respondents appeared to be representative of the overall program alumni population with respect to basic demographics, such as gender, nationality, and class year.

\section{REFEREN CES}

Battistoni, Richard. 1997. "Service Learning as Civic Learning: Lessons We Can Learn from Our Students." In Education for Citizenship: Ideas and Innovations in Political Learning, eds. Grant Reeher and Joseph Cammarano, 31-5o. Lanham, MD: Rowman \& Littlefield.

Davidson, Dan. 2007. "Study Abroad and Outcomes Measurements: The Case of Russian.” Modern Language Journal 91 (2): 276-80.

Dwyer, M.M. 2004. "More is Better: The Impact of Study Abroad Program Duration." Frontiers: The Interdisciplinary Journal of Study Abroad 10: 151-63.

Engle, Lilli, and John Engle. 2003. "Study Abroad Levels: Toward a Classification of Program Types." Frontiers: The Interdisciplinary Journal of Study Abroad 9: 1-20.

Fobes, Catherine. 2005. "Taking a Critical Pedagogical Look at Travel-Study Abroad: 'A Classroom with a View' in Cusco, Peru." Teaching Sociology 33 (2): 181-94.

Fowler, Michael. 2005. "Transplanting Active Learning Abroad: Creating a Stimulating Negotiation Pedagogy across Cultural Divides." International Studies Perspectives 6 (2): 155-73

Fraga, Luis, Terri Givens, and Dianne Pinderhughes. 2011. Political Science in the 21st Century. Washington, DC: American Political Science Association.

Fry, Gerald W., R. Michael Paige, Jae-Eun Jon, Jon Dillow, and Kyoung-Ah Nam. 2009. "Study Abroad and its Transformative Power." Occasional Papers on International Educational Exchange 32.

Institute of International Education. 2011. "Duration of U.S. Study Abroad, 200o/ 01-2009/10." Open Doors Report on International Educational Exchange. Retrieved from http://www.iie.org/opendoors.

Jacoby, Barbara, and Nevin C. Brown. 2009. "Preparing Students for Global Civic Engagement." In Civic Engagement in Higher Education: Concepts and Practices, eds. Barbara Jacoby and Associates, 213-26. San Francisco, CA: Jossey-Bass.

Kuo, Eric, and Ryan Fehr. 2011. UMD Study Abroad Survey: 2010-2011 Edition. College Park, MD: Cultural Adjustment Project.

Lutterman-Aguilar, Ann, and Orval Gingerich. 2002. "Experiential Pedagogy for Study Abroad: Educating for Global Citizenship." Frontiers: The Interdisciplinary Journal of Study Abroad 8: 41-82.

Paige, R. Michael, Gerald W. Fry, Elizabeth Stallman, Jasmina Josic, and Jae-Eun Jon. 2009. "Study Abroad for Global Engagement: The Long-Term Impact of Mobility Experiences." Intercultural Education 20 ( $\left.\mathrm{S}_{1-2}\right)$ : $\mathrm{S}_{29}-\mathrm{S}_{44}$. 